\title{
Transmission Line Capacity Enhancement with Unified Power Flow Controller Considering Loadability Analysis
}

\author{
Yusuf Samuel Sunday", Jimoh Boyi, Okorie Patrick Ubeh, Abubakar Adamu Saidu, \\ Momoh Illiasu Onimisi
}

Department of Electrical Engineering, Ahmadu Bello University Zaria, Kaduna State, Nigeria

*Corresponding author: yusufssamuel@gmail.com, Tel: +2348073248176

\begin{abstract}
This paper proposes transmission line capacity enhancement with optimal location and sizing of UPFC on IEEE 14bus network. This is necessary because of the increase in load growth with every passing day without an equivalent increase of line capacity which has brought many power systems closer to their stability limit. The dynamic and practical application of this proposed method is achieved by increasing linearly, the loading factor $(\lambda)$ from 1.25 to 1.50 of the base case value of 1.0 and then, its effect is investigated. In each of the increment, the power flow result is obtained using Newton-Raphson method, while the optimal location and sizing of UPFC are done using Grey Wolf Optimization (GWO) technique. This approach will help the bulk dispatcher of power to plan ahead so as to meet and supply the ever-growing in the demand for adequate and reliable power system as a result of population growth, improved living standards and technological advancement. The efficacy of the proposed method is verified on a standard IEEE 14-bus system. The simulation results show the effectiveness and suitable performance of the proposed methodology at enhancing transmission capacity and deferring or eliminating for transmission line upgrading.
\end{abstract}

Keywords: Line Loadability, UPFC, Grey Wolf Optimizer, Voltage Stability, Overloading

(C) 2019 Penerbit UTM Press. All rights reserved

Article History: received 6 August 2019; accepted 27 September 2019; published 18 December 2019.

\section{INTRODUCTION}

The increase in demand for electricity and the deregulation of the power sector have led to a non-discriminatory and competitive situation in the electric market space, thereby pressing transmission lines closer or beyond their stability limit [1]. This deregulatory policy has allowed for countless participation in the power sector and resulted in line overloading and congestion of transmission lines [2]. Since electrical energy is an essential ingredient upon which a country's development is anchored, there is therefore an unending demand for this energy [3]. As the demand for a stable, secure, economical, adequate and reliable power supply keep increasing along with population and technological advancement, there exist problems of high congestion, power loss, instability of voltage, frequency collapse, inadvertent loop flow, transient instability. Voltage collapse and line overload are still regarded as the biggest threats to the transmission system [4]. Transmission line power carrying capacity is limited by three main factors; thermal limit, voltage-drop limit and steady-state stability limit, others are: voltage quality limit, voltage stability margin, Joule losses limit etc. [5]. Thermal limit concerns with the line parameters and geographical location and the voltage-drop limit depends on the line parameters and loading, the steadystate stability does not only concerns with the line alone but also involves characteristics of the power system [6].
These problems and other factors result in power system insecurity [7, 8]. Building a new generating unit or transmission lines to cater for the expansion and demand, is constrained by huge rising cost, environmental impact and long construction time. These challenges have greatly necessitated for the optimization of the existing networks to accommodate more power transmission during both normal and contingency conditions [9-12]. In order to solve the problems of inadequate supply, voltage instability and high power losses on the network, installing a new and robust device that can enhance transmission line transfer capacity and network's efficiency on the existing transmission line will be a viable solution. This is because apart from the tendency of less investment cost, it will have little or no adverse effects on the environment. The need for the installation of such a robust device is what gave birth to advanced power electronics based devices called Flexible Alternating Current Transmission System (FACTS).

FACTS devices are evolving technology based solution that can enhance controllability, security, system loadability and increase transmission line transfer capacity [13]. It offers a superior adaption to varying operational conditions and enhances the usage of existing transmission installations. Among the various FACTS devices that are available, Unified Power Flow Controller (UPFC) has a unique ability to provide a flexible control of the bus voltage magnitude and active and reactive power flow 
through the line, in which, it is connected $[14,15]$. UPFC performance greatly depends on the location and sizing in the system and as such GWO is used.

In this paper, GWO is used for the optimal location and sizing of UPFC because it is flexible, scalable, and has a special capability to strike the right balance between the exploration and exploitation during the search which leads to favourable convergence.

\section{MODELLING OF UNIFIED POWER FLOW CONTROLLER}

The UPFC comprises of two switches based on the voltage source converter (VSC) valves as shown in Figure 1. DC links the two converters together. Transmission line is connected to series inverter through series (boosting) transformer. The shunt inverter is connected together to a local bus through a shunt-connected (exciting) transformer. The inverted (shunt) serves as both generator and absorber of active and reactive power. It also offers the role of independent advance static VAR compensator by providing power compensation for the transmission line. The series (converter 2) is utilized to produce voltage source at the fundamental frequency with variable amplitude $\left(0 \leq V_{T} \leq V_{T \max }\right)$ and phase angle $\left(0 \leq \emptyset_{T} \leq\right.$ $2 \pi$ ), this is added to the AC transmission line by the series connected boosting transformer. Figure 1 shows a typical operating principle of UPFC.

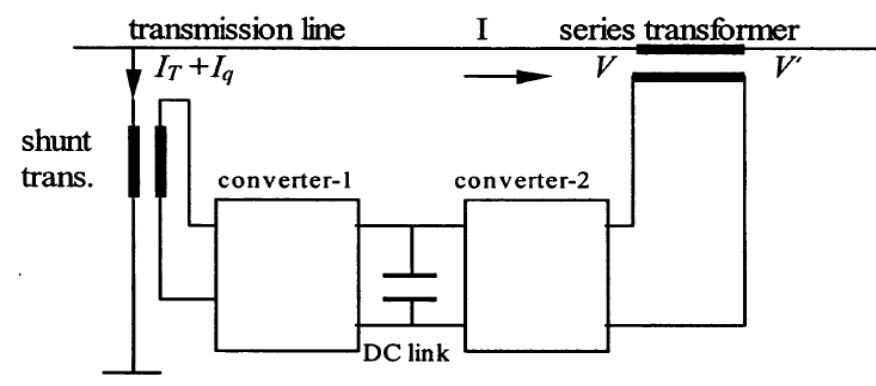

Figure 1. The Operating principle of UPFC $[15,16]$

The real power and reactive power injection at the bus- $i$ with the system loading $(\lambda)$ is obtained using:

$$
\begin{aligned}
& P_{i}=P_{g i}-P_{d i}^{0}(1+\lambda) \\
& Q_{i}=Q_{g i}-Q_{d i}^{0}(1+\lambda)=\sum_{j \in N_{b}} Q_{i j}
\end{aligned}
$$

Where $P_{d i}^{0}$ and $Q_{d i}^{0}$ are the initial real and reactive power demand. $P_{g i}$ and $Q_{g i}$ are the real and reactive power generations at bus- $i$ respectively. It is assumed that in equations (1) and (2), that a uniform loading with the same increase in loading factor of the power demand at all the P$\mathrm{Q}$ buses have been considered and is to be taken care of by the reference bus, whereas, sharing of generation amongst the generators can easily be incorporated in this model [15].

\subsection{Grey Wolf Optimization Technique}

GWO is a nature-inspired metaheuristics technique developed on the basis of the leadership hierarchy and hunting characteristics of grey wolf (Canis lupus) by [17]. Wolves are social animal of four divisions in the hierarchical order of alpha $(\alpha)$, beta $(\beta)$, delta $(\delta)$, and omega $(\omega)$ [18]. Figure 2 shows the social hierarchy of grey wolves. There are three main phases of hunting; tracking the prey, encircling the prey and attacking towards the prey. Hunting in the pack is carried out by alpha, beta and delta. Alpha with supreme dominant in a pack determines the fittest due to its best knowledge for searching prey, while the beta is the subordinate with second best solution and delta gives the third best solution, while gamma is the other candidate solutions [19]. The algorithm has proven to have wider exploitation and exploration of the unknown search spaces than the previous Swarms Intelligent [17].

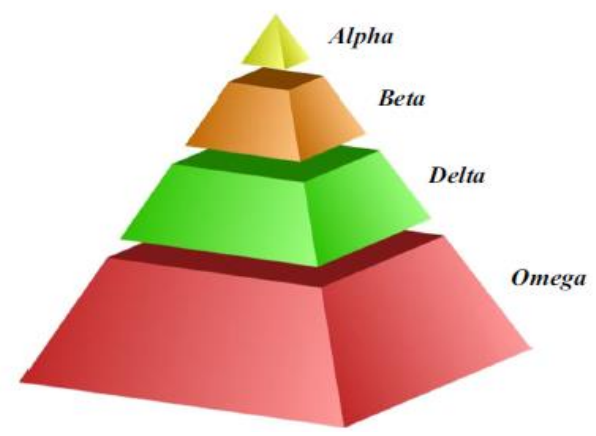

Figure 2. Social hierarchy of grey wolves [19]

(a) Encircling prey

The distance between wolf and prey is mathematically model as follows:

$$
\begin{aligned}
& \vec{H}=\left|\vec{A} \cdot \vec{B}_{\text {prey }}(t)-\vec{B}(t)\right| \\
& \vec{B}(t+1)=\vec{B}_{\text {Prey }}(t)-\vec{S} \cdot \vec{H}
\end{aligned}
$$

Where;

$\mathrm{t}$ indicates the current iteration

$\overrightarrow{\mathrm{S}}$ and $\overrightarrow{\mathrm{A}}$ are coefficient vectors,

$\vec{B}_{P}$ is the position vector of the prey,

$\overrightarrow{\mathrm{B}}$ the grey wolf vector position

The vectors $\vec{S}$ and $\vec{A}$ are calculated as shown below:

$\vec{S}=2 \vec{a} \cdot \vec{r}_{1}-\vec{a}$, and $\vec{A}=2 \cdot \vec{r}_{2}$

$\vec{a}$ is linearly decrease from 2 to $0, \mathrm{r} 1$ and $\mathrm{r} 2=[0,1]$

\section{(b) Hunting}

Hunting in a pack is carried out by alpha, beta and delta. It is a process of moving towards the prey using the shared information obtained among the wolves in equation (3) and (4) respective. The alpha, beta and delta positions are model by:

$$
\begin{aligned}
& \vec{H}_{\alpha}=\left|\vec{A}_{1} \cdot \vec{B}_{\alpha}-\vec{B}\right|, \vec{H}_{\beta}=\left|\vec{A}_{2} \cdot \vec{B}_{\beta}-\vec{B}\right|, \vec{H}_{\delta}= \\
& \left|\vec{A}_{3} \cdot \vec{B}_{\delta}-\vec{B}\right| \\
& \vec{B}_{1}=\vec{B}_{\alpha}-\vec{S}_{1} \cdot\left(\vec{H}_{\alpha}\right), \quad \vec{B}_{2}=\vec{B}_{\beta}-\vec{S}_{2} \cdot\left(\vec{H}_{\beta}\right), \\
& \vec{B}_{3}=\vec{B}_{\delta}-\vec{S}_{3} \cdot\left(\vec{H}_{\delta}\right) \\
& B_{(t+1)}=\frac{\vec{B}_{1}+\vec{B}_{2}+\vec{B}_{3}}{3}
\end{aligned}
$$




\section{OPTIMAL POWER FLOW PROBLEM FORMULATION}

The objective of this paper is to enhance power system security during increase in the system loadability of an interconnected network:

(i) Minimization of Real Power Loss Minimize $F_{\text {loss }}(x, y)$

Subject to: $h(x, y)=0, g(x, y) \leq 0$

$$
\min F_{\text {loss }}=\sum_{k=1}^{N_{l}}\left[G_{k}\left(V_{i}^{2}+V_{j}^{2}-2 V_{i} V_{j} \cos \theta_{i j}\right)\right.
$$

Where $h$ is the equality constraint representing typical load flow equations (active and reactive power balance equation) and $g$ is the system operating constraint that includes generator voltages, their real and reactive power outputs and shunt compensation. $\left(F_{\text {loss }}\right)$ is the active power loss, $G_{k}$ is the conductance of branch $\mathrm{k}, V_{i}$ and $V_{j}$ are the magnitude of voltage at sending end and receiving end buses respectively and $\theta_{i j}$ is the phase angle difference between $i^{\text {th }}$ and $j^{\text {th }}$ bus.

\section{(ii) Voltage Deviation (VD)}

This objective function is aimed at improving the voltage profile by minimizing the voltage deviation at all load buses. This is mathematically expressed as follows:

$$
F_{V D}=\min (V D)=\min \left(\sum_{k=1}^{N}\left|V_{i}-V_{j}^{r e f}\right|^{2}\right)
$$

Where $V_{i}$ is the bus voltage at bus $i$ and $V_{j}^{\text {ref }}$ reference voltage limit at bus $j$.

\section{Equality Constraints}

The Active and reactive power equality constraint is given by:

$$
\begin{aligned}
0=P_{G i}-P_{D i}- & V_{G i} \sum_{j \in N i}^{N b} V_{j}\left(G_{i j} \cos \theta_{i j}\right. \\
& \left.+B_{i j} \sin \theta_{i j}\right) \quad \text { for } i \in N_{b}
\end{aligned}
$$

The Reactive power equality constraint is defined by:

$$
\begin{gathered}
0=Q_{G i}-Q_{D i}-V_{G i} \sum_{j \in N i}^{N b} V_{j}\left(G_{i j} \sin \theta_{i j}+B_{i j} \cos \theta_{i j}\right) \\
i \in N_{b}
\end{gathered}
$$

Where $N_{b}$ is the total number of buses, $P_{G i}$ is the total real power generation, $P_{D i}$ is the total power demand, $Q_{G i}$ is the generation of reactive power, $Q_{D i}$ is the reactive power demand, $G_{i j}$ and $B_{i j}$ denote conductance and susceptance between $i^{\text {th }}$ and $j^{\text {th }}$ bus respectively.

\section{Operational Inequality Constraints}

The dynamic and static inequality constraints for both generator and network limits are expressed in terms of lower and upper limits as follows:

$$
\begin{array}{ll}
V_{G i}^{\min } \leq V_{G i} \leq V_{G i}^{\max } & i \in N_{b} \\
Q_{\text {geni }}^{\text {min }} \leq Q_{\text {geni }} \leq Q_{\text {geni }}^{\max } & i \in N_{b} \\
T_{i}^{\text {min }} \leq T_{i} \leq T_{i}^{\text {max }} & k=1 \ldots \ldots, N T \\
P_{\text {geni }}^{\text {min }} \leq P_{\text {geni }} \leq P_{\text {geni }}^{\max } & k=1 \ldots \ldots, N T \\
Q_{\text {Shi }}^{\text {min }} \leq Q_{\text {shi }} \leq Q_{\text {shi }}^{\max } & k=1 \ldots \ldots, N T
\end{array}
$$

\section{RESULT AND DISCUSSION}

\section{A. Case-1: Loadability Analysis at Normal Loading Condition $(\lambda=\mathbf{1 . 0})$}

For the normal loading condition $(\lambda=1.0)$, load flow analysis was carried out based on Newton-Raphson technique on IEEE 14-bus network. The base case total power loss of the network is $28.9178 \mathrm{MW}$, but in the presence of UPFC size 59.2600MVAr optimally located on the network using GWO at bus 5, yields a reduction of $21.1349 \mathrm{MW}$ representing $26.9139 \%$ average real power improvement across the entire network, under the operating range of 0.95-1.05p.u.

The voltage profile plot before and after UPFC placement is shown in Figure 3 under normal loading $(\lambda=1.0)$ condition. It is observed that bus $14(0.9426 \mathrm{p} . \mathrm{u})$ has the lowest base voltage magnitude and violates $\pm 5 \%$ tolerance margin of the nominal voltage criterion, but after optimal placement of UPFC it is observed that the voltage profile has been enhanced to 0.9624 p.u. The base case voltage magnitude is represented with blue colour, the voltage without UPFC is denoted using red colour and the network with UPFC is represented by green colour. At normal loading, it is observed from the voltage profile result that an overall voltage profile improvement of $8.08 \%$ was achieved on the entire network.

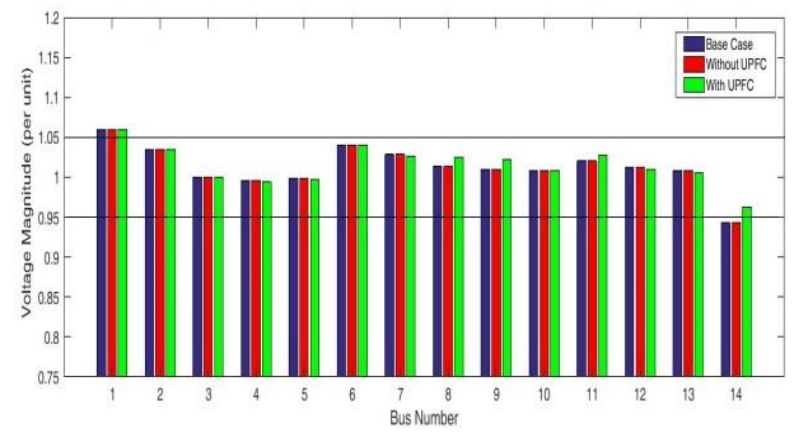

Figure 3. Voltage profile result under normal loading $(\lambda=1.0)$ condition

\section{B. Case-2: Loadability Analysis at Moderate Loading Condition $(\lambda=1.25)$}

From the load flow analysis of IEEE 14-bus network with increase in load level by $\lambda=1.25$ from the nominal (base case). The load growth results in increase of power loss in lines 1 (13-14), 2 (12-13), 3(6-13) and 4(6-12) by $5.55 \mathrm{MW}, 2.90 \mathrm{MW}, 1.89 \mathrm{MW}$ and $1.64 \mathrm{MW}$ respectively when compared to base case nominal loading condition $(\lambda=1.0)$. The highest losses occur between lines 1(13-14) because of the nearer connections to the critical lines and the distance from the generating units. Total power loss of $39.9028 \mathrm{MW}$ is obtained and after the installation of UPFC at Bus 14 (the bus that shows a high vulnerability to 
voltage collapse) the loss reduces to $26.7575 \mathrm{MW}$ represents $32.9433 \%$ power loss reduction with 47.9200MVAr UPFC size.

Figure 4 shows a voltage profile result before and after installing UPFC under moderate loading $(\lambda=1.25)$ condition, under the operating range voltage of 0.95 1.05 p.u. It is clearly observable that bus 14 has the minimum base voltage of $0.9407 \mathrm{p} . \mathrm{u}$ and after optimal placement of UPFC it increases to 1.0140 p.u. It is also noticed that with the application of UPFC, an average voltage profile improvement of $22.30 \%$ is achieved on the entire load buses.

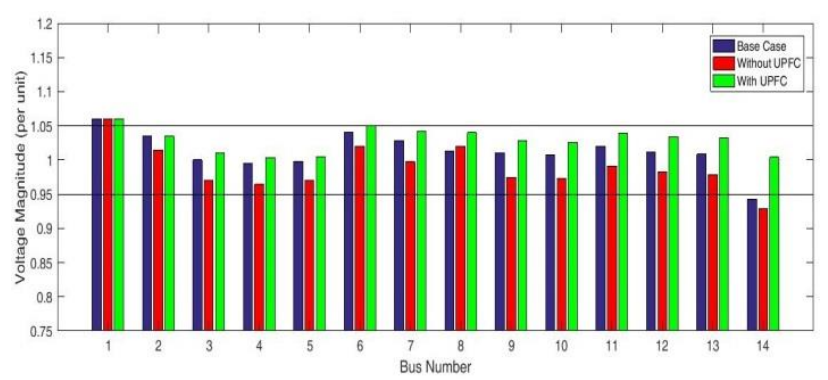

Figure 4. Voltage profile results under moderate loading $(\lambda=1.25)$ condition

\section{Case-3: Loadability Analysis at Critical Loading Condition $(\lambda=\mathbf{1 . 5 0})$}

In the power flow results of IEEE 14-bus network under increase in loading factor of $\lambda=1.50$. It is identified that lines 1(13-14), 2(12-13), 3(6-13) and 4(6-11) power loss increase by $5.94 \mathrm{MW}, 3.40 \mathrm{MW}$ and $2.86 \mathrm{MW}$ respectively. An overall real power loss of 58.4950MW is obtained and after optimal placement of UPFC, it reduces to $28.7330 \mathrm{MW}$ representing $50.8996 \%$ with installation of 78.3200MVar size of UPFC at bus 5 .

The voltage profile for the critical loading $(\lambda=1.50)$ is shown in Figure 5, violation of voltages nominal tolerance of $\pm 5 \%$ was recorded in Buses 9, 10 and most especially Bus 14, due to the cascading effects. The other load buses like 4, 5, 6, 7, 12 and 13 were very close to their lower limits of voltage amplitude, which means that any slight increase in load demand will result in voltage collapse. It is therefore concluded that the loading factor of $\lambda=1.50$ is the optimum loadability of IEEE 14-bus system under the operating range of 0.95-1.05p.u. With an optimal location of UPFC at Bus 5, it shows voltage stability enhancement on the entire buses by increasing the voltage stability margin of the system to enable more power to be transmitted over existing network. The voltage magnitude has an overall improvement of $22.07 \%$ with UPFC. Table 1 shows the summary of the simulation results for UPFC placement and total power loss reduction.

\subsection{CONCLUSION}

This paper proposes GWO-based algorithm for optimal location and sizing of UPFC on IEEE 14-bus test system for power loss minimization and voltage deviation reduction. Load flow and steady-state stability analyses were performed to determine if the system voltages under different load variations are within acceptable bounds under a specified system state (0.95-1.05p.u). The load buses have been increased in the loading factor $(\lambda)$ from
1.25 to 1.50 from their nominal value of 1.0. This proposed method will help bulk energy dispatcher with the necessary information needed to transmit more power without comprising voltage stability and with the application of UPFC to enhance system security. This approach was used for analysis to show if increasing linearly the load demand for all buses to a certain load demand is possible. The results show that utilization of UPFC at an appropriate location in the power system would reduce the amount of active and reactive power losses and also effectively improve the voltage profile of the system. Finally, it can be concluded that more power can be transmitted to meet ever-growing demand over an existing network without compromising the voltage stability by using the cheaper plan proposed in this methodology.

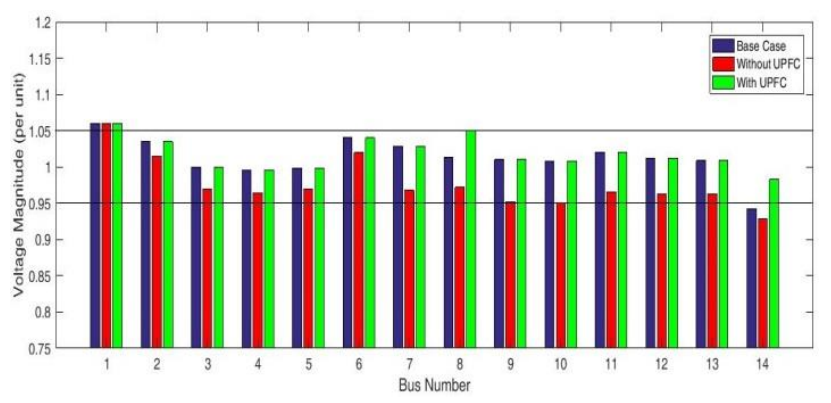

Figure 5. Voltage profile results under critical loading factor $(\lambda)$ of 1.50

Table 1. Summary of the results for IEEE 14-Bus under different loading condition with and without UPFC

\begin{tabular}{cccccc}
\hline $\begin{array}{c}\text { Loading } \\
\text { Factor }\end{array}$ & $\begin{array}{c}\text { Losses } \\
\text { Without } \\
\text { UPFC } \\
\text { (MW) }\end{array}$ & $\begin{array}{c}\text { Rating } \\
\text { of } \\
\text { UPFC } \\
\text { (MVAr) }\end{array}$ & $\begin{array}{c}\text { Losses } \\
\text { With } \\
\text { UPFC } \\
\text { (MW) }\end{array}$ & $\begin{array}{c}\text { UPFC } \\
\text { Location }\end{array}$ & $\begin{array}{c}\text { \% Power } \\
\text { Loss } \\
\text { Reduction }\end{array}$ \\
\hline $\begin{array}{c}\text { Normal } \\
(\lambda=1.0)\end{array}$ & 28.9178 & 59.2600 & 21.1349 & 5 & 26.9139 \\
& & & & & \\
$\begin{array}{c}\text { Moderate } \\
(\lambda=1.25)\end{array}$ & 39.9028 & 47.9200 & 26.7575 & 14 & 32.9433 \\
& & & & & \\
\hline $\begin{array}{c}\text { Critical } \\
(\lambda=1.50)\end{array}$ & 58.4950 & 78.3200 & 28.7330 & 5 & \\
& & & & & \\
\hline
\end{tabular}

\section{REFERENCES}

[1] I. A. Araga, A. O. Anibasa, and I. I. Alabi, "Placement of Multiple Svc on Nigerian Grid System for Steady State Operational Enhancement," American Journal of Engineering Research (AJER), vol. 6, pp. 78-85, 2017.

[2] A. Pillay, S. Prabhakar Karthikeyan, and D. P. Kothari, "Congestion management in power systems - A review," International Journal of Electrical Power \& Energy Systems, vol. 70, pp. 83-90, 2015/09/01/ 2015.

[3] K. O. Ignatius, A. O. Emmanuel, and A. O. Patrick, "Load Flow Assessment of the Nigeria 330-kV 
Power System," American Journal of Electrical and Electronic Engineering, vol. 5, pp. 159-165, 2017.

[4] M. J. Vahid-Pakdel, H. Seyedi, and B. MohammadiIvatloo, "Enhancement of power system voltage stability in multi-carrier energy systems," International Journal of Electrical Power \& Energy Systems, vol. 99, pp. 344-354, 2018/07/01/ 2018.

[5] J. D. Glover, M. S. Sarma, and T. J. Overby, Power System Analysis and Design. Stamford, USA: Global Engineering Publishers, 2012.

[6] S. Quaia, "Critical analysis of line loadability constraints," International Transactions on Electrical Energy Systems, p. e2552, 2018.

[7] J. J. Paserba, "How FACTS Controllers Benefit AC Transmission Systems," IEEE Press, 2003.

[8] T. G. Manohar and R. S. Reddy, "Literature Review on Voltage stability phenomenon and Importance of FACTS Controllers In power system Environment," Global Journal of Researches in Engineering Electrical and Electronics Engineering, vol. 12, pp. 24-29, 2012.

[9] S. Raj and B. Bhattacharyya, "Optimal placement of TCSC and SVC for reactive power planning using Whale optimization algorithm," Swarm and Evolutionary Computation BASE DATA, pp. 1-29, 2017.

[10] A. O. Emmanuel, K. O. Ignatius, and E. A. Abel, "Enhancement of Power System Transient Stability A Review," IOSR Journal of Electrical and Electronics Engineering (IOSR-JEEE), vol. 12, pp. 32-36, 2017.

[11] M. V. Suganyadevi and C. K. Babulalb, "Estimating of Loadability Margin of a Power System by comparing Voltage Stability Indices," International Conference on "Control, Automation, Communication and Energy Conservation, pp. 1-5, 2009.
[12] S. Ratra, R. Tiwari, and K. R. Niazi, "Voltage stability assessment in power systems using line voltage stability index," Computers \& Electrical Engineering, 2018/01/05/ 2018.

[13] N. G. Hingorani and L. Gyugyi, "Understanding FACTS: Concepts and Technology of Flexible AC Transmission Systems.," Wiley-IEEE Press: New York, NY, 1998.

[14] S. Ravindra, C. V. Suresh, S. Sivanagaraju, and V. C. Reddy, "Power System Security Enhancement with Unified Power Flow Controller under Multievent Contingency Conditions," Ain Shams Engineering Journal, pp. 1-10, 2015.

[15] K. S. Verma, S. N. Singh, and H. O. Gupta, "Location of unified power flow controller for congestion management," Electric Power Systems Research, vol. 58, pp. 89-96, 2001/06/21/ 2001.

[16] X. P. Zhang, C. Rehtanz, and B. Pal, Flexible AC Transmission Systems: Modelling and Control. Heidelberg New York Dordrecht London: Springer, 2012.

[17] S. Mirjalili, S. Mohammad, and A. Lewis, "Advances in Engineering Software Grey Wolf Optimizer," Advances in Engineering Software, vol. 69, pp. 46-61, 2014.

[18] L. D. Mech, "Alpha status, dominance, and division of labor in wolf packs," Can. J. Zool, vol. 77, pp. 1196-1203, 1999.

[19] D. P. Ladumor, R. H. Bhesdadiya, I. N. Trivedi, and P. Jangir, "Optimal Power Flow with Shunt Flexible AC Transmission System (FACTS) Device Using Grey Wolf Optimizer," 3rd International Conference on Advances in Electrical, Information Communication and Bio-Informatics (AEEICB17), 2017. 